rev.relac.int.estrateg.segur.5(1):103-117,2010

\title{
LOS VÍNCULOS ENTRE SEGURIDAD HUMANA, MEDIO AMBIENTE Y TERRORISMO: COMUNIDAD, VULNERABILIDAD E INTERDEPENDENCIA EN LA SUBREGIÓN AMAZÓNICA
}

\author{
Fabián Ramírez Cabrales*
}

\section{RESUMEN}

Los vínculos entre seguridad humana, medio ambiente y terrorismo indican diversos campos de estudio donde confluyen varias disciplinas y se fusionan preocupaciones relacionadas con la seguridad transnacional y nacional. Este enfoque permite incluir cualquier amenaza de naturaleza política, estratégica, económica, social o ecológica. Bajo estos términos, las características de la subregión amazónica reflejan un escenario conflictivo y carente de regímenes de seguridad que amenaza con acentuar la vulnerabilidad de todos los países de la región.

Palabras clave: seguridad humana, vínculos, comunidad, vulnerabilidad, interdependencia, Amazonas.

\footnotetext{
* Candidato a Doctor en Relaciones Internacionales e Integración Europea, programa impartido por la Universidad Autónoma de Barcelona. DEA en Derecho Internacional Público y Relaciones Internacionales por la Universidad Autónoma de Barcelona. Máster en Iniciación a la Investigación en Relaciones Internacionales e Integración Europea por la Universidad Autónoma de Barcelona. Profesor Militar y Teniente de Navío Administrativo en Relaciones Internacionales. rc.fabian@gmail.com
} 


\begin{abstract}
The relations between human security, environment and terrorism show various fields of study where several disciplines come together, and concerns related to transnational and national security combine. This approach allows us to include any threat of political, strategic, economic, social or ecological nature. Under these conditions, the characteristics of the Amazon sub-region reflect a conflictive scenario devoid of security regimes that threatens to accentuate the vulnerability of all the countries of the region.
\end{abstract}

Key words: human security, links, community, vulnerability, interdependence, Amazon.

\title{
INTRODUCCIÓN
}

Los vínculos entre seguridad humana, medio ambiente y terrorismo constituyen un gran reto para los países de la subregión amazónica. Este espacio está comprendido por ocho países vecinos y un territorio europeo de ultramar correspondiente al Departamento de la Guayana Francesa. Tiene una extensión de 7’590.083 kilómetros cuadrados y una población estimada de treinta millones de habitantes distribuidos en centros urbanos y rurales. La Amazonia alberga el $50 \%$ de la diversidad del planeta, estimado entre 5 y 30 millones especies, con sólo 1.5 millones de especies clasificadas. Asimismo, se caracteriza por ser una de las cuencas del mundo más ricas en ríos, selvas y recursos energéticos. Sin embargo, la Amazonía ha pasado de ser un espacio vacío, a un espacio ocupado y en constante construcción y deconstrucción, con un crecimiento demográfico sostenido, lleno de conflictos por el acceso y la apropiación de su patrimonio natural y, con ello, el dominio territorial. Ante este panorama, estas acciones no sólo han profundizado la amenaza ambiental sobre el Amazonas sino que también es considerado como territorio fértil para el desarrollo de actividades criminales que atentan contra la seguridad humana.

La seguridad humana es un concepto que se centra primordialmente en las personas y modifica el concepto de la seguridad, asociada tradicionalmente con la defensa del Estado, frente a agresiones externas para enfocarlo en un nuevo paradigma que se concentre en la protección de la población contra toda gama de amenazas. Por ejemplo, los abusos a los derechos humanos, la degradación del medioambiente, el terrorismo internacional, la delincuencia transnacional organizada, entre otros, son contingencias que vulneran la integridad de los individuos a nivel global. En consecuencia, la seguridad humana inserta a la seguridad internacional como una nueva alternativa de pensamiento en el marco de la seguridad y cohabita con una concepción individuo-céntrica. En tal sentido, la seguridad humana no es excluyente frente al estrecho enfoque estatocéntrico de la seguridad nacional y, por el contrario, «Cuando la seguridad de las personas es atacada en cualquier parte del mundo, es probable que todos los países resulten involucrados» ${ }^{1}$. Bajo esta perspectiva, este artículo se

\footnotetext{
${ }^{1}$ PNUD (Programa de las Naciones Unidas para el Desarrollo). Informe sobre Desarrollo Humano $1994:$ Nuevas dimensiones de la Seguridad Humana. Fondo de Cultura Económica, México, p. 26.
} 
propone identificar los vínculos entre seguridad humana, el medio ambiente y terrorismo en la subregión amazónica. Para ello, este trabajo inicia con una descripción geográfica del territorio en cuestión para comprender el escenario en donde se proyectan las amenazas a la comunidad amazónica y el aspecto demográfico. En segundo lugar, se examina la definición y características de la seguridad humana, haciendo un especial énfasis en términos de interdependencia. Esta revisión teórica nos permitirá delimitar el concepto de la seguridad humana. Seguidamente, centraremos nuestra atención en las amenazas a la seguridad ambiental y a la seguridad personal señalando las vulnerabilidades que aquejan a la subregión amazónica. En cuarto y último lugar realizamos un balance conceptual en torno a las amenazas estudiadas y el enfoque estatocéntrico. Este cotejo final nos permitirá concluir que los vínculos entre seguridad humana, medio ambiente y terrorismo acentúan la vulnerabilidad de todos los países de la región.

\section{CONTEXTO GEOGRÁFICO: LA AMAZONÍA}

«La Amazonia es diversa, heterogénea y compleja por excelencia; es multidimensional, pero integral, desde los aspectos biofísicos, socioeconómicos, sociopolíticos y socioculturales». "La Amazonía es un territorio socio-bio-geográfico que va desde el estuario o archipiélago de la Isla Marajo, a nivel del mar Atlántico, en el Estado de Pará en Brasil, hasta las nieves perpetuas de la cordillera de los Andes, en Perú, y se caracteriza por ser una de las cuencas del mundo más ricas en ríos, selvas, recursos energéticos y biodiversidad». La Amazonía traspasa los límites de las fronteras políticas de los ocho países que la componen (Bolivia, Brasil, Colombia, Ecuador, Guyana, Perú, Surinam y Venezuela), ocupando las cuencas de los ríos Orinoco y del propio Amazonas, junto a toda el área de sus afluentes, a través de los que penetra al norte del continente en los territorios de Guyana, Surinam y Guayana Francesa, Ilegando hasta el Mar Caribe en una extensión de 7’590.083 kilómetros cuadrados. Hacia el Oriente, alcanza el Océano Atlántico, luego de iniciar su travesía al noroeste de Sudamérica con las nacientes del río Marañón².

Las cuencas hidrográficas del Orinoco y Amazonas le permiten poseer un caudal combinado de 138.000 metros cúbicos por segundo (Orinoco $18.000 \mathrm{~m}^{3}+$ Amazonas $120.000 \mathrm{~m}^{3}$ ), lo que convierte a esta subregión en la reserva de agua dulce más importante del planeta. El río Orinoco se encuentra al Norte de Sudamérica y cruza por los territorios de Brasil, Colombia y, en su mayoría, por Venezuela. Constituye una cuenca en forma de «U» que nace en la Amazonía y desemboca en el océano Atlántico. En cuanto al río Amazonas, localizado en el norte de Sudamérica, es el río más largo de Brasil y del mundo, en términos de su cuenca hidrográfica, número de afluentes, longitud y volumen de agua transportada. «En este espacio drenan aproximadamente 1.100 ríos de diferente

\footnotetext{
${ }^{2}$ BERNAL, Hernando. (2004). «Amazonia, entre la integración regional y la globalización», Revista Luna Azul, 02, 01, p. 1-3.

${ }^{3}$ OTCA (Organización del Tratado de Cooperación Amazónica). Agua. Plan estratégico de la Organización del Tratado de Cooperación Amazónica (2004-2012). p.16.
} 
tipo de orden y magnitud, de los cuales predomina el cauce principal del río Amazonas con una extensión de 6.742 kilómetros»³. Este río es el responsable de la producción de la quinta parte del agua dulce de todo el planeta que no está congelada, además de una enorme cantidad de especies animales que habitan en sus aguas. El 90\% del curso del Amazonas desde su nacimiento es navegable, constituyendo una red de más de $50.000 \mathrm{Km}$. de vías fluviales en su cauce y el de sus afluentes.

Por otra parte, alberga el $50 \%$ de la diversidad del planeta, estimado entre 5 y 30 millones de especies, con sólo 1.5 millones de especies clasificadas. Aproximadamente, el $39 \%$ de los recursos renovables globales se encuentran en el continente americano, y su superficie cubre 1/3 de la América del Sur. Provee el 50\% del consumo mundial de oxígeno y cuenta con una de las reservas minerales y agrícolas más grandes del mundo: tiene excelentes yacimientos de bauxita, estimados en 200 millones de toneladas (ley del 50\%); de estaño, más rico aún que el de Malasia; de manganeso y de hierro, que son los mayores del mundo; en madera hay 59 especies para extraer celulosa, 247 para construcción y 29 para artefactos navales; yacimientos de calcáreos, de sal y de sal gema; es bastante rica en hidrocarburos, a más de su inmenso potencial agrícola ${ }^{4}$.

\section{ASPECTOS DEMOGRÁFICOS}

La población total de la Amazonia en la actualidad es difícil de determinar debido al restringido acceso a los territorios, a la dispersión de los asentamientos, a la baja y precaria capacidad institucional en las zonas periféricas de la Amazonía, entre otras. Aún así, se calcula que la Amazonia tiene aproximadamente 30 millones de habitantes distribuidos en centros urbanos y rurales. La mayor concentración demográfica se presenta en las ciudades de Belem, Manaos, Río Branco, Porto Velho, Macapa y Boa Vista, en Brasil; Iquitos, Pucallpa y Puerto Maldonado, en Perú; Cobijo, Trinidad y Santa Cruz, en Bolivia; Zamora, Puyo, Macas y Loja, en el Ecuador; Florencia, San José del Guaviare y Leticia, en Colombia, entre otras. En menor dinámica demográfica, pero concentrados en las capitales provinciales de los espacios amazónicos del arco del norte del Amazonas, se encuentran los Estados de Guyana, Surinam, Venezuela y el departamento de ultramar de la Guayana Francesa.

Desde los años sesenta hasta la actualidad la dinámica demográfica de la Amazonia se ha caracterizado por su constante aumento. Por lo tanto, ha pasado de ser un espacio vacío a un espacio ocupado y en constante construcción y deconstrucción, afectado por el acceso y la apropiación de su patrimonio natural y, con ello, el dominio territorial ${ }^{5}$. Incluso, es relevante el acceso de agentes extra-amazónicos que, en la mayoría de las veces, no contemplan las especificidades del entorno y menos aún el respeto a sus pobladores tradicionales en contravía de la seguridad humana.

\footnotetext{
${ }^{4}$ BERNAL, Op. cit., p. 1-3.

${ }^{5}$ Ibid., p. 1-3.
} 


\section{LA SEGURIDAD HUMANA}

El término seguridad humana fue acuñado en 1994 por la Organización de Naciones Unidas, en el marco del Programa de las Naciones Unidas para el Desarrollo PNUD, y publicado en su Informe sobre Desarrollo Humano: Nuevas dimensiones de la seguridad humana. Actualmente, este concepto ha sido estudiado por un gran número de expertos y publicado en diversas investigaciones académicas que señalan el carácter multidimensional, interdependiente, universal y preventivo de dicha expresión. Es multidimensional, en el sentido que la seguridad humana intenta establecer aquellas dimensiones que afectan a la seguridad de las personas en siete componentes (seguridad alimentaria, seguridad ambiental, seguridad en la salud, seguridad económica, seguridad personal, seguridad de la comunidad y seguridad política) e «identifica amenazas y vulnerabilidades tradicionales y no convencionales que afectan a la colectividad, superando los marcos meramente criminológicos» ${ }^{6}$. También es cierto que, si bien analíticamente son distinguibles, estos componentes forman parte de una noción (seguridad humana) que hacen de este concepto un argumento indivisible. Dicho de otra manera, las inseguridades que afectan a una de las dimensiones, afectarán también al conjunto de ellas, es decir, es interdependiente. De igual forma, es universal porque hay muchas amenazas que son comunes a toda la comunidad, como el desempleo, los estupefacientes, el delito, la contaminación y las violaciones de los derechos humanos. De la misma forma, es preventiva en el sentido que sería menos costoso y de mayor nivel humanitario atender esas amenazas desde las bases hacia la cima y es mejor hacerles frente de forma anticipada, en lugar de hacerlo cuando ya han aparecido los problemas ${ }^{7}$.

La seguridad humana es un concepto que se centra primordialmente en las personas y modifica el concepto de la seguridad asociada tradicionalmente con la defensa del Estado frente a agresiones externas, para enfocarlo en un nuevo paradigma que se concentre en la protección de la población contra toda una gama de amenazas. De igual forma, Fernández señala que ya no son los Estados los únicos agentes implicados: las organizaciones regionales e internacionales, las organizaciones no gubernamentales y la sociedad están involucradas en la gestión de las cuestiones de seguridad. En ese sentido, «la seguridad humana y la seguridad del Estado se refuerzan mutuamente y dependen cada vez más una de la otra ${ }^{8}$. Vista desde este enfoque, la seguridad humana robustece la seguridad del Estado, pero no la sustituye. Entiende, por otra parte, que los seres humanos somos cada vez más interdependientes y vulnerables. Debido a esta interdependencia, la vulnerabilidad de unos es también la vulnerabilidad de todos ${ }^{9}$.

\footnotetext{
${ }^{6}$ FERNÁNDEZ, Juan P. (2005) «Seguridad Humana». Director, Dr. Manuel Ballbé Mallol. Universidad Autónoma de Barcelona. Departamento de Derecho Público y Ciencias Histórico-Jurídicas. p.39. (Tesis doctoral).

7 PNUD (Programa de las Naciones Unidas para el Desarrollo). Informe sobre Desarrollo Humano 1994: Nuevas dimensiones de la Seguridad Humana. Cap. 2. p. 25-28.
}

${ }^{8}$ FERNÁNDEZ, Op. cit., p.82.

${ }^{9}$ Ibid p., 57.

Fabián Ramírez Cabrales 
En ese sentido, Nef reafirma la idea de vulnerabilidad mutua señalando que en un sistema global altamente interconectado, la seguridad del mismo está condicionada por los subsistemas más débiles. En otros términos, «(...) mientras exista vulnerabilidad e inseguridad extrema en algunos sectores del conjunto, todos somos, en cierta medida, vulnerables» ${ }^{10}$. En consecuencia, "estas amenazas pueden provenir de actores estatales o no estatales y los medios para enfrentarlas no solo requieren el fomento al desarrollo humano y una eficaz acción gubernamental, sino también involucra sanciones colectivas y, como último recurso, el uso de la fuerza» ${ }^{11}$. Este nuevo tipo de amenazas internas o transnacionales no pueden ser contenidas dentro de las fronteras del Estado. Por consiguiente, para hacer frente a la diversidad de problemas que ponen en peligro a individuos, grupos y sociedades, es necesaria la cooperación -justamente por el carácter transnacional de estas nuevas amenazas-. En resumen, la inseguridad que se observa hoy día es de carácter transnacional, desdibujando las fronteras y erosionando las soberanías.

\section{LA SEGURIDAD HUMANA EN TÉRMINOS DE INTERDEPENDENCIA}

La estabilidad política y la seguridad del Estado están amenazadas por muchos factores que exceden las capacidades inherentes a su propia soberanía. Desde los años setenta el paradigma transnacionalista de las relaciones internacionales hizo evidente que las amenazas no se limitaban sólo a amenazas militares -sino que estas se habían multiplicado- y ya no podían ser contenidas por las fronteras nacionales. La pobreza, la degradación medio ambiental, el terrorismo, el crimen organizado internacional, entre otros, hay que verlos en términos de tendencias globales y fuerzas que afectan a los individuos y comunidades. «Las preocupaciones por la seguridad humana estarían relacionadas, en buen grado, con los efectos de ese proceso de globalización, principalmente con las repercusiones que este tiene sobre la seguridad y el bienestar de cualquier lugar del mundo» ${ }^{12}$. Los resultados de esta interdependencia hacen difícil la separación de la seguridad del Estado y de la seguridad humana. Asimismo, "las intimidaciones que se ciernen sobre las personas en muchos lugares del mundo, se convierten en las verdaderas amenazas a la seguridad del Estado» ${ }^{13}$. De este modo, la realidad internacional comienza a interpretarse en términos de globalidad.

Lo anterior implica que los actores internacionales no escapen al «efecto boomerang», indicado por Liotta, debido a la interconexión de los problemas en el plano mundial. Si los Estados no le

\footnotetext{
${ }^{10}$ NEF, Jorge. "Seguridad Humana y Vulnerabilidad Mutua», en Francisco Rojas Aravena y Moufida Goucha (compiladores), Seguridad Humana, Prevención de Conflictos y Paz en América Latina y el Caribe, Santiago, UNESCO/FLACSO-CHILE: 2002. p. 30.

${ }^{11}$ BAJPAI, Kanti. (2000). «Human Security: Concept and Measurement», en: Kroc Institute Occasional Paper No. 19:OP:1, Notre Dame. p. 31 (traducción libre).

${ }^{12}$ LIOTTA, Peter. (2003). «Boomerang Effect: The Convergence of National and Human Security», Security Dialogueo, 33, 4, p. 472 (traducción libre).

${ }^{13}$ Ibid. p., 485
} 
prestan suficiente atención a esos nuevos problemas, se producirá el efecto que los devolverá a la propia casa. Por consiguiente, los Estados no pueden por sí solos hacer frente a los problemas transnacionales. La seguridad básica, los derechos humanos, los temas sociales globales, como la protección del medio ambiente, deben ser resueltos cooperativamente. En otros términos, «las nuevas cuestiones transnacionales no saben de jurisdicciones territoriales ni respetan alineamientos políticos existentes y requieren de la cooperación internacional para su efectiva resolución» ${ }^{14}$. Evidentemente, las fronteras nacionales ya no son el mar que delimita estos nuevos peligros para la seguridad humana.

Asimismo, la globalización también tiene otra característica respecto de la rápida evolución a que asistimos en el concepto de seguridad: la creciente vulnerabilidad respecto de cuestiones que antes parecían lejanas o sin repercusión. «Esa vulnerabilidad es un rasgo característico de esta realidad internacional puesto que no se sabe de dónde pueden proceder los peligros y no ponen en riesgo únicamente al Estado sino que pueden atentar directamente contra la dimensión humana o individual» ${ }^{15}$. Según el criterio de las relaciones causales y globales, cuando lo exterior y lo interior se aproximan, no es fácil mantener fuera de los muros a las amenazas globales y tampoco mantener dentro, bajo control, a las redes criminales. «Las redes internacionales de narcotráfico o el terrorismo son algunas de esas nuevas fuerzas que no son producto de los Estados nacionales y que son irreductibles a la fuerza de los mismos» ${ }^{16}$.

\section{LAS AMENAZAS A LA SEGURIDAD AMAZÓNICA}

Los atentados del 11 de Septiembre demostraron que no es posible garantizar la seguridad interior si no se logra garantizar un sistema de seguridad global -resultante de la cooperación interestatalque haga hincapié en el concepto de Seguridad Humana. La Resolución 1373 de las Naciones Unidas, aprobada en 2001, deja de manifiesto cuáles son las amenazas a ser neutralizadas a fin de reducir la vulnerabilidad de los Estados en un escenario globalizado y de alta interdependencia ${ }^{17}$. De igual forma, la Declaración sobre Seguridad OEA ${ }^{18}$, que entre los aspectos más importantes da prioridad a la seguridad humana y a la determinación de las amenazas, destaca la enérgica condena a toda forma de terrorismo, crimen organizado transnacional, incluyendo el narcotráfico, corrupción, trata de personas, lavado de activos y otros delitos, y la necesidad de enfrentar de manera cooperativa,

\footnotetext{
${ }^{14}$ HELD, David. y MCGREW, Anthony. (2003). Globalización/antiglobalización. Barcelona, Paidós editor. p. $29-30$.

${ }^{15}$ FERNÁNDEZ, Op. cit., p. 137.

${ }^{16}$ Ibid. Op. cit., p. 137.

${ }^{17}$ La Resolución ONU 1373 (2001) identifica como amenazas graves a la seguridad internacional: el terrorismo internacional y la delincuencia transnacional organizada, las drogas ilícitas, el blanqueo de dinero, el tráfico ilícito de armas y la circulación ilícita de materiales nucleares, químicos, biológicos y otros materiales potencialmente letales.
}

${ }^{18}$ Declaración sobre Seguridad en las Américas, 28 de octubre de 2003, ciudad de México: México. 
decidida e integral estas amenazas, de acuerdo con lo establecido en los respectivos ordenamientos constitucionales, las legislaciones nacionales y en los instrumentos internacionales, especialmente las convenciones de la Organización de Estados Americanos, actualmente vigentes y aplicables sobre estos temas.

En ese sentido, Flores señala que la subregión amazónica después del 11 de septiembre ha ganado relevancia, pues se presenta como un espacio potencialmente conflictivo ${ }^{19}$. "La debilidad institucional de los Estados que cuentan con soberanía sobre este territorio genera incentivos que posibilitan el asentamiento de organizaciones criminales transnacionales, en especial aquellas relacionadas con el narcotráfico y el crimen organizado -contemplados dentro de la lucha contra el terrorismo-» ${ }^{20}$. Ante este panorama, este tipo de ilícitos no solo han profundizado la amenaza ambiental sobre el Amazonas sino que también la subregión debe ser «considerada como territorio fértil para el desarrollo de actividades criminales, dada la débil presencia estatal ${ }^{21}$. Dicha caracterización continúa siendo hoy en día un desafío para muchos Estados del conjunto amazónico, distinguidos por una falta de soberanía efectiva en su territorio, es decir, la acción del Estado no llega efectivamente a la totalidad de su espacio y ciudadanos ${ }^{22}$. Analicemos en detenimiento estos dos componentes que afectan la seguridad humana de la subregión.

\section{AMENAZAS A LA SEGURIDAD AMBIENTAL AMAZÓNICA}

Conforme con Astrid Arrarás y Eduardo Gamarra ${ }^{23}$ se comparte el hecho de que el tráfico de drogas es uno de los muchos factores que plantean una amenaza seria para la estabilidad y la paz de los ocho países que comparten el Amazonas. Específicamente, el enfoque propuesto describe cómo los cultivos ilícitos, la producción de drogas ilegales y su eventual tráfico afectan el medio ambiente en este espacio vital. Arrarás y Gamarra sostienen que estas actividades, que por su parte generan la acción ilícita adicional, tienen consecuencias directas e indirectas sobre el medio ambiente. En efecto, los cultivos ilícitos han causado varios problemas ambientales en la subregión amazónica. La tala de árboles es ambientalmente el efecto destructivo más visible del cultivo de la hoja de coca. Las estimaciones por deforestación registran que los agricultores en Bolivia, Colombia

\footnotetext{
${ }^{19}$ FLORES, Mário C. Reflexões Estratégicas: Repensando a Defesa Nacional. É Realizações. São Paulo. 2002. p.17-28.

20 SAMPÓ, Carolina (2003). «Brasil y la región amazónica después del 11 de Septiembre: desafíos y oportunidades", Argentina Global, 14, p. 104.

${ }^{21}$ SAMPÓ, Op. cit., p. 101.

${ }^{22}$ GRIFFITHS, John (2009). «Procesos de integración regional en defensa: ¿Consejo Sudamericano de Defensa UNASUR- Un nuevo intento?», Revista Globalización, Gobernabilidad y Competitividad, 3, 1, p. 113.
}

${ }^{23}$ ARRARÁS, A. y GAMARRA, E. (2002): «Drug Trafficking, National Security, and the Environment in the Amazon Basin" en Woodrow Wilson Center Report of the Americas; Tulchin, Joseph S. y Golding, Heather A., (eds): Enviroment and Security in the Amazon Basin, No.4. Washington, D.C, 75-98 (traducción libre). 
y Perú han recurrido al desmonte manual y quema inducida de bosque tropical ${ }^{24}$. Estas técnicas, por lo demás incorrectas, erosionan el suelo eliminando la materia vegetativa necesaria para estabilizarse y reducen los depósitos minerales del suelo vitales para la rotación de cultivos. El aire, el suelo y la contaminación del agua son también efectos negativos incidentales del cultivo de coca en el Amazonas.

Evidentemente, la quema de bosque tropical para extender los cultivos ilícitos genera contaminación atmosférica; asimismo, la contaminación del agua es también efecto negativo colateral del cultivo de la coca. Ciertamente, los cultivadores, en aras de maximizar la producción, dependen en gran medida de los pesticidas, herbicidas y fertilizantes. El uso de estos productos químicos se traduce en la contaminación casi inmediata del suelo y canales de suministros de agua. En el valle superior de Huallaga, Perú, las estimaciones registraron que los cultivadores de hoja de coca aplicaron 1.5 millones de litros de «paraquat» como pesticida ${ }^{25}$, y cuyo impacto puede contaminar y erradicar la flora y la fauna de la región. En Perú y Colombia, el uso excesivo de fertilizantes provoca crecimiento anormal de algas en los ríos y, por lo tanto, reduce las poblaciones de peces y plantas endémicas. No obstante lo anterior, quizás la consecuencia total más seria tiene que ver con la fase real de la producción. Una amplia variedad de productos químicos empleados como precursores se utiliza en el proceso y producción de drogas. La mayoría de estos productos químicos no se produce en los países de la subregión amazónica, se importan legalmente de los Estados Unidos y Europa para ser después empleados de manera ilegal por parte de organizaciones criminales. Según fuentes oficiales, el tráfico ilícito de precursores químicos se ha convertido en una actividad igual de rentable a la producción y tráfico de cocaína.

Ahora bien, el vertimiento de estos productos químicos sobre la tierra y en los ríos ha dado lugar a la degradación ambiental. Los expertos han estimado que más de 100 millones de litros de basura tóxica se han descargado en los ríos en Perú y Colombia. El vertimiento de estos productos químicos disminuye niveles del agua, reduce disponibilidad del oxígeno y elimina varias especies de plantas y animales; específicamente, se ha identificado la existencia de contaminación química en sectores fluviales del río Caquetá, en Colombia, y del valle superior de Huallaga, en Perú. Además de la contaminación del suelo y el agua, la producción de drogas en laboratorios clandestinos requiere de una gran cantidad de mano de obra que genera el desplazamiento de flujos migratorios hacia la subregión. Este movimiento masivo no planificado de masas exacerba la presión en el medio ambiente. En suma, estas amenazas producen la degradación ambiental de la subregión amazónica.

\footnotetext{
${ }^{24}$ LLOYD, Lewis III (1998). «Peru, Coca Trade, and Environment» Trade and Environment Database Cases Studies, 8, 1, Case number 437 (traducción libre).

${ }^{25}$ SCOTT, Carl y ULLMER, Deborah M. (1992). «Coca Trade and Production» Trade and Environment Database Cases Studies, 1, 1, Case number 16 (traducción libre).
} 


\section{AMENAZAS A LA SEGURIDAD PERSONAL EN EL AMAZONAS}

Hasta aquí se ha podido identificar que la subregión amazónica se presenta como potencialmente conflictiva, teniendo en cuenta las características geoestratégicas de la misma, la débil presencia estatal en dicho territorio y la proliferación de nuevas amenazas, como consecuencia de la primera, son insuficiencias a observar. Nótese que este tipo de «carencias posibilitan la creación de Zonas Grises que generan incentivos para el asentamiento de actores transnacionales capaces de minar el orden internacional vigente, tales como el narcotráfico, el crimen organizado y el terrorismo. Estas problemáticas hacen difícil la distinción entre seguridad interna y externa, generando la imposición de una agenda interméstica ${ }^{26}$. En consecuencia, la seguridad va más allá de las fronteras, la agenda de seguridad se amplía y las amenazas se vuelven transnacionales ${ }^{27}$. No en vano, la «...creciente ofensiva policial y militar sobre los tradicionales santuarios insurgentes obligará, con bastante seguridad, a las FARC, ELN y AUC a buscar refugio más allá de las fronteras ${ }^{28}$. Evidentemente, Ruiz sostiene que desde la década de los 80 se dio un modus vivendi tácito entre los grupos guerrilleros colombianos y el gobierno ecuatoriano que le permitía a este último no malgastar recursos en la frontera norte y concentrar tropas en la frontera sur con el Perú. De igual forma, señala en su artículo, publicado en el año 2006, que las FARC han concentrado sus esfuerzos en esta región no solo por ser un corredor estratégico básico para el tráfico ilegal que alimenta su actividad sino porque militarmente permite tomar la frontera ecuatoriana como centro de refugio y abastecimiento. De hecho, agrega, las columnas de las FARC mantienen campamentos allí y sus líderes encuentran una forma de evadir la presión del Ejército colombiano, pudiendo llegar incluso a las más importantes ciudades ecuatorianas ${ }^{29}$. Evento que ya advertía Carlos Malamud en el año 2002.

Prueba de ello constituye la ubicación y posterior destrucción del campamento permanente de las FARC, ubicado en territorio ecuatoriano a 1.800 metros de la línea de frontera que comparte con Colombia, el primero de marzo de 2008. Al respecto, el gobierno de Colombia ha señalado que «cuenta con información precisa que le permite aseverar, sin temor a equívocos, que el campamento hallado en territorio ecuatoriano no era un lugar de tránsito sino, por el contrario, un campamento permanente» ${ }^{30}$, es decir, en términos de Sampó, lo que se denomina una Zona Gris para albergar y

\footnotetext{
${ }^{26}$ SAMPÓ, Op. cit., p. 103.

27 Para citar un ejemplo de dicha afirmación cítese a Carlos Malamud. Este investigador ya advertía que «la lucha del gobierno colombiano contra la delincuencia organizada, se llame esta narcotráfico, terrorismo, contrabando de armas o de precursores químicos, lavado de dinero, corrupción, etc., amenaza de forma constante y creciente con extenderse a los países vecinos, algunos de los cuales ya han comenzado a sentir los primeros coletazos de un problema de difícil y lenta solución». Ver MALAMUD, Carlos (2003): «El largo camino para la paz en Colombia. Las difíciles relaciones de Colombia con sus vecinos (1a parte)», en: Real Instituto Elcano, WP 26, Madrid. p. 3.

28 Ibid., p. 3.

${ }^{29}$ RUIZ, Juan (2006). "Seguridad y Defensa de Ecuador: Espejismos y arenas movedizas», Security and Defense Studies Review, 6, 1, p. 69-70 (traducción libre).

30 Discurso del Embajador de Colombia ante la Organización de Estados Americanos, Camilo Ospina, miércoles 05 de marzo 2008.
} 
ofrecer refugio a actores transnacionales. Este delicado evento confirma la deducción expuesta años atrás por Malamud, quien no duda en afirmar que «la represión y los crecientes obstáculos al funcionamiento tanto del terrorismo como del narcotráfico y de otras formas de delincuencia organizada tienen el riesgo de aumentar la corrupción en los países vecinos, en la búsqueda de refugios y garantías para la prosecución de la acción delictiva» ${ }^{31}$. No obstante, el panorama fronterizo colombo-ecuatoriano tiende a ser más agudo; de acuerdo con International Crisis Group, Ecuador es un tránsito y punto de almacenamiento para la droga colombiana y peruana. Asimismo, se registran corredores estratégicos para el contrabando de precursores químicos, los cuales son trasladados desde allí a sus vecinos, y el país se ha hecho cada vez más atractivo para el blanqueo de dinero debido a la dolarización de su economía ${ }^{32}$.

Sin embargo, la amenaza más preocupante es la que viene bajando otra vez por los ríos fronterizos. A medida que el Plan Colombia combate los cultivos ilícitos en el departamento de Putumayo, la coca desciende hacia las selvas despobladas del Amazonas. Esta tendencia se evidenció con las imágenes del satélite brasileño que vigila las fronteras con Perú, Colombia y Venezuela, en las cuales se revelaron el pasado 16 de marzo de 2008 cultivos de coca y laboratorios clandestinos para la elaboración de droga en la selva amazónica de Brasil. Las imágenes de satélite reportadas registran cuatro claros en la selva donde se cultiva el arbusto y se ubica un laboratorio para procesar la coca a unos 150 kilómetros de la ciudad de Tabatinga, Brasil, cerca de la frontera norte. TabatingaLeticia es una vía de dos manos. Pasa la cocaína y retornan los insumos químicos, porque para refinar la hoja de coca es necesario, éter, acetona e insumos químicos que Colombia, Perú y Bolivia no posee. Adicionalmente, en las cuatro hectáreas del cultivo también fueron descubiertas dos pistas clandestinas de aterrizaje. Para Mauro Spósito, delegado de la Policía Federal de Brasil en Tabatinga, la Amazonía colombo-brasileña es una selva de rutas. Un inmenso espacio vacío por el que circulan en la segunda flota de avionetas privadas más grande del mundo -la brasileñadrogas prohibidas de Colombia a las Guyanas, Surinam o la frontera con Paraguay, y de allí a Europa o Sudáfrica, armas y, sobre todo, municiones hacia Colombia (Montesinos 1999 -con los 10.000 fusiles jordanos- se encargó de resolver el problema de armamento a las Farc) $)^{33}$. Por lo que respecta a Bolivia, este país es el tercer principal productor de hoja de coca del mundo, representando el $18 \%$ del cultivo a nivel mundial. "La superficie dedicada al cultivo de coca aumentó un $8 \%$ respecto de 2005, y alcanzó 27.500 hectáreas en 2006» ${ }^{34}$. En suma, podemos afirmar que el narcotráfico, el terrorismo y el crimen organizado son las actividades ilícitas que más afligen a la zona. Todas las cuales afectan a la seguridad de las personas y erosionan las capacidades de los Estados amazónicos.

\footnotetext{
${ }^{31}$ MALAMUD, Op. cit., p.3.

32 INTERNATIONAL CRISIS GROUP (2008). Latin America Report, N25 (traducción libre).

33 EL TIEMPO (2003). Editorial Especial. En los confines de Colombia. p. 37.

${ }^{34}$ NACIONES UNIDAS (2007). «Informe Mundial sobre las drogas», Oficina contra la Droga y el Delito. p. 202.
} 


\section{UN ALTO EN EL CAMINO A MODO DE BALANCE}

Hasta aquí se puede inferir que las amenazas a la seguridad ambiental y personal en la subregión amazónica poseen un carácter trasnacional, multidimensional y participan actores y agentes que, en la mayoría de los casos, no representan a una nación o no se sitúan en un territorio estatal claramente delimitado; corresponden a actores no estatales. Aún más, los riesgos y vulnerabilidades que perturban a la seguridad ambiental y personal de cualquiera de los Estados amazónicos, inciden simultáneamente -en términos de interdependencia- en más de un país y, por lo tanto, no pueden resolverse exclusivamente dentro de sus propias fronteras.

Lo anterior significa que estas inseguridades trascienden el esquema clásico de la seguridad nacional. En ese sentido, la seguridad humana es complementaria de la seguridad estatal, no la reemplaza; este es un aspecto esencial del concepto. En consecuencia, la seguridad demanda una acción multilateral y a la vez una comprensión de los problemas locales considerando la naturaleza de las amenazas. Bajo esa perspectiva, la cooperación en la subregión amazónica resulta un instrumento efectivo para hacerles frente y lograr reducirlas de manera importante. Ello sugiere, la construcción de un régimen internacional que señale los procedimientos, leyes, normas y principios para atender las problemáticas comunes y, particularmente, para la toma de decisiones resulta imprescindible.

Sin embargo, la subregión amazónica después del 11 de septiembre se presenta como un espacio potencialmente conflictivo en el que predomina el enfoque realista de las relaciones internacionales. Este enfoque enfatiza en la conflictividad y esto significa que no se dimensiona de manera adecuada la cooperación entre los diferentes actores y estrategias comunes a implementar. En consecuencia, si no existen las bases para la correcta estructuración de un régimen tenderán a prevalecer los intereses inmediatos de los actores o de las coaliciones con más poder y, con ello, la incertidumbre y la tensión serán una constante en la subregión.

\section{CONCLUSIONES}

Observado este panorama se puede afirmar que hasta la fecha ha sido materialmente imposible establecer una estrategia común que permita al conjunto de los países amazónicos avanzar decididamente en definir los vínculos que existen entre seguridad humana, medio ambiente y terrorismo. Asimismo, en el ámbito regional, no se ha logrado alcanzar un consenso -más allá de lo discursivo- teniendo en cuenta las distintas percepciones y posiciones de los países implicados frente a estas amenazas y las estrategias a ser desarrolladas para enfrentarlas. Ello evidencia una falta de unidad intra-regional para atender las amenazas a la seguridad humana. En consecuencia, si los Estados no le prestan suficiente atención a esos nuevos problemas, se producirá lo que Liotta ha denominado el efecto boomerang. Dicho de otra manera, los devolverá a la propia casa. Por tanto, es inminente la construcción de un régimen subregional de seguridad donde los actores identifiquen la existencia de una agenda de intereses y políticas comunes en torno a los cuales la 
cooperación subregional hace más eficiente su solución. Los regímenes cooperativos son oportunos, porque coordinando políticas gubernamentales previenen y contienen las amenazas a los intereses nacionales y evitan, como sostienen Robledo y Rojas, que las percepciones que de estas tienen los Estados se transformen en tensiones, crisis o abiertas confrontaciones. De lo contrario, la subregión amazónica continuará siendo un escenario altamente conflictivo en donde los vínculos entre seguridad humana, medio ambiente y terrorismo acentúan la vulnerabilidad de todos los países de la región.

\section{BIBLIOGRAFÍA}

- $\quad$ ARRARÁS, A. y GAMARRA, E. (2002): «Drug Trafficking, National Security, and the Environment in the Amazon Basin» en Woodrow Wilson Center Report of the Americas; Tulchin, Joseph S. y Golding, Heather A., (eds): Enviroment and Security in the Amazon Basin, No.4. Washington, D.C, 75-98.

- BERNAL, Hernando (2004). «Amazonia, entre la integración regional y la globalización», Revista Luna Azul, 02, 01, 1-10.

- $\quad$ Castañeda, Jorge (2003): «The Forgotten Relationship», Foreign Affairs, mayo-junio, 67-81.

- BAJPAI, Kanti. (2000). «Human Security: Concept and Measurement», en: Kroc Institute Occasional Paper No. 19:OP:1, Notre Dame. p. 1-64.

- BERNAL, Hernando. (2004). «Amazonia, entre la integración regional y la globalización», Revista Luna Azul, 02, 01. P. 1-10.

- CAVAGNARI FILHO, G. (2002). «Introdução à defesa da Amazônia», Carta Internacional, ano $X, n^{\circ} 107-108$. p. 19-21.

- $\quad$ CHÁVEZ, H. (2008). Mensaje anual al Congreso de la República Bolivariana de Venezuela.

- FERNÁNDEZ, Juan P. (2005) «Seguridad Humana». Director, Dr. Manuel Ballbé Mallol. Universidad Autónoma de Barcelona. Departamento de Derecho Público y Ciencias HistóricoJurídicas. (Tesis doctoral).

- $\quad$ FLORES, Mário C. Reflexões Estratégicas: Repensando a Defesa Nacional. É Realizações. São Paulo. 2002. p.17-28. 
- $\quad$ GRIFFITHS, John (2009). «Procesos de integración regional en defensa: ¿Consejo Sudamericano de Defensa -UNASUR- Un nuevo intento?», Revista Globalización, Gobernabilidad y Competitividad, 3, 1, p. 104-119.

- $\quad$ HELD, David. y MCGREW, Anthony. (2003). Globalización/antiglobalización. Barcelona, Paidós editor.

- $\quad$ INTERNATIONAL CRISIS GROUP (2008). Latin America Report, Nº25.

- $\quad$ KEOHANE, Robert O. After Hegemony - Cooperation and Discord in the World Political Economy. Princeton University Press. Princeton, N.J. 1984.

- $\quad$ LIOTTA, Peter. (2003). «Boomerang Effect: The Convergence of National and Human Security», Security Dialogueo, 33, 4. p. 473-488

- $\quad$ LLOYD, Lewis III (1998). «Peru, Coca Trade, and Environment» Trade and Environment Database Cases Studies, 8, 1, Case number 437.

- $\quad$ MALAMUD, Carlos (2003): «El largo camino para la paz en Colombia. Las difíciles relaciones de Colombia con sus vecinos ( ${ }^{\text {a }}$ parte)», en: Real Instituto Elcano, WP 26, Madrid.

- $\quad$ NACIONES UNIDAS (2007). «Informe Mundial sobre las drogas», Oficina contra la Droga y el Delito.

- NEF, Jorge. "Seguridad Humana y Vulnerabilidad Mutua», en Francisco Rojas Aravena y Moufida Goucha (compiladores), Seguridad Humana, Prevención de Conflictos y Paz en América Latina y el Caribe, Santiago, UNESCO/FLACSO-CHILE: 2002.

- $\quad$ PNUD (Programa de las Naciones Unidas para el Desarrollo). Informe sobre Desarrollo Humano 1994: Nuevas dimensiones de la Seguridad Humana. Fondo de Cultura Económica, México.

- $\quad$ RAMALHO DA ROCHA, Antonio J. (2007): «Políticas de buena vecindad y confianza mutua: el caso brasileño» en Isidro Sepúlveda editores: Seguridad Humana y nuevas políticas de defensa en Iberoamérica, Instituto Universitario General Gutiérrez Mellado, Madrid.

- $\quad$ ROBLEDO, M. y ROJAS F. (2002). «Construyendo un régimen cooperativo de seguridad en el Cono Sur de América Latina. Elementos conceptuales, políticos y estratégicos» en Fasoc, año $17, N^{\circ} 1-N^{\circ} 2$, p. 5-31. 
- $\quad$ RUIZ, Juan (2006). «Seguridad y Defensa de Ecuador: Espejismos y arenas movedizas», Security and Defense Studies Review, 6, 1, p. 58-81.

- SAMPÓ, Carolina (2003). «Brasil y la región amazónica después del 11 de septiembre: desafíos y oportunidades», Argentina Global, 14. p. 100-117.

- $\quad$ SCOTT, Carl y ULLMER, Deborah M. (1992). «Coca Trade and Production» Trade and Environment Database Cases Studies, 1, 1, Case number 16.

- $\quad$ OTCA (Organización del Tratado de Cooperación Amazónica). Agua. Plan estratégico de la Organización del Tratado de Cooperación Amazónica (2004-2012). 